\title{
Realization of Multi-material Polymer Parts by Simultaneous Laser Beam Melting
}

\author{
Tobias LAUMER ${ }^{* 1-3}$, Thomas STICHEL ${ }^{* 1-2}$, Daniel RIEDLBAUER ${ }^{* 2,5}$, \\ Philipp AMEND ${ }^{* 1-2}$, Julia MERGHEIM ${ }^{* 2,5}$ and Michael SCHMIDT ${ }^{* 1-4}$ \\ ${ }^{*}$ blz Bayerisches Laserzentrum GmbH, Konrad-Zuse-Str. 2-6, D-91052, Erlangen, Germany \\ ${ }^{* 2}$ CRC 814 Additive Fertigung, Friedrich-Alexander-University, Erlangen-Nürnberg, Germany \\ *3 SAOT Erlangen Graduate School in Advanced Optical Technologies, Erlangen, Germany \\ ${ }^{* 4}$ LPT Institute of Photonic Technologies, Friedrich-Alexander-University, Erlangen-Nürnberg, Germany \\ ${ }^{* 5}$ LTM Chair of Applied Mechanics, Friedrich-Alexander-University, Erlangen-Nürnberg, Germany
}

\begin{abstract}
In this paper, first results regarding the realization of multi-material parts by Simultaneous Laser Beam Melting (SLBM) of polymers are presented. This new approach allows the layerwise generation of parts consisting of different polymer materials within one building process. Besides the typical advantages of additive manufacturing technologies, such parts can fulfill different product requirements concomitant and therefore could enlarge the overall field of application. The powder materials used for this paper are polyethylene (PE) and a polyamide based thermoplastic elastomer (TPE). After depositing the powder materials next to each other, infrared-emitters heat the lower melting polymer and a $\mathrm{CO}_{2}$ laser provides the preheating temperature of the higher melting polymer. In the last step, a thulium fibre laser melts the two preheated powders simultaneously. The realized specimens are characterized by cross sections and their tensile strengths are determined. Additionally, the new approach of the simultaneous energy irradiation is investigated using a Finite Element Analysis in order to gain a more profound process understanding. In that sense, the influence of the size of the exposure area on the reachable maximum temperatures inside that area was analyzed by the simulation and compared to experimental studies.
\end{abstract}

DOI: $10.2961 /$ jlmn.2015.02.0006

Keywords: Additive Manufacturing, Simultaneous Laser Beam Melting of Polymers, Multi-Material Parts, New Materials

\section{Introduction}

Laser Beam Melting (LBM) of polymers has evolved from first manufactured parts in 1986 [1] into an important manufacturing technique for building prototypes or parts in small series. By melting preheated polymer powders layerwise by selective energy deposition, geometrical freedom is offered which cannot be achieved with other technologies like milling or injection molding. In accordance with Levy [2], LBM offers the highest achievable mechanical part properties for additively manufacturing polymer parts and only by Laser Beam Melting of metal powders higher mechanical part properties can be achieved.

In the process, a semi-crystalline thermoplastic polymer powder is deposited homogeneously on a building platform by layer thicknesses between 100 and $200 \mu \mathrm{m}$. The powder is preheated by infrared emitters a few degrees below the melting temperature of the used polymer and afterwards molten by a galvano scanner guided $\mathrm{CO}_{2}$ laser. After melting the layer geometry, the building platform is lowered by a defined layer thickness and a new powder layer is deposited.
By using LBM during the product development and testing phase, prototype parts can be realized within single days and needed modifications can be quickly adapted. Decreasing time-to-markets lead to time and cost savings and thus to competitive advantages during the overall product life cycle $[3,4]$. With increasing complexity, products are often built by different polymer materials and thus the need for multi-material prototypes is an increasing requirement by the industry, which cannot be achieved by single material parts generated by conventional LBM. Therefore, Simultaneous Laser Beam Melting (SLBM) as a new Additive Manufacturing technology offers the possibility to build parts consisting of different materials. SLBM can process different polymer powders in order to achieve multi-material parts with different properties regarding stiffness or chemical resistances. Besides former works about new mechanisms for depositing different powder materials [5], the optical material behavior and heat conduction of polymer powders and their influence on the melting process were analyzed [6,7] as important basic research regarding the realization of multi-material parts. 
In this paper, PE and TPE powder materials are processed to multi-material parts by SLBM. Achieved multi-material parts are analyzed regarding the forming of a boundary zone between the different materials by means of cross sections. Additionally, tensile strengths of specimens built out of single and multiple materials are determined and compared to allow a quantitative analysis of the achievable mechanical properties. Concerning the simultaneous irradiation concept, the influence of the size of the exposure area on the reachable maximum temperatures inside the illuminated area is investigated by a FEM simulation model and compared to real experiments.

\section{Experimental}

\subsection{Simultaneous Laser Beam Melting}

In the SLBM process, three different energy sources are used to preheat and melt the powder materials. Besides infrared emitters, a $\mathrm{CO}_{2}$ laser $(\lambda=10.6 \mu \mathrm{m})$ and a thulium laser $(\lambda=1.94 \mu \mathrm{m})$ are used. First, different powder materials are deposited next to each other by a two-chamber deposition mechanism and infrared emitters heat both materials a few degrees below the melting temperature of the lower melting polymer, like shown in figure 1.

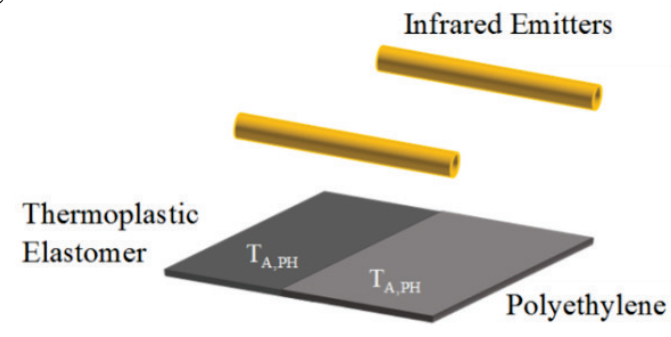

Fig. 1 Process steps of SLBM: Preheating of polymer with lower melting point by infrared emitters

As next process step, the higher melting polymer has also to be heated. In order to allow a homogeneous energy and thus temperature distribution, a diffractive optical element (DOE) is used to shape the beam of a $\mathrm{CO}_{2}$ laser. The DOE forms a rectangular beam cross section with a flat-top intensity. By the combined energy deposition of infrared emitters and homogenous irradiation by the $\mathrm{CO}_{2}$ laser, both polymers are warmed to their preheating temperatures (figure 2).

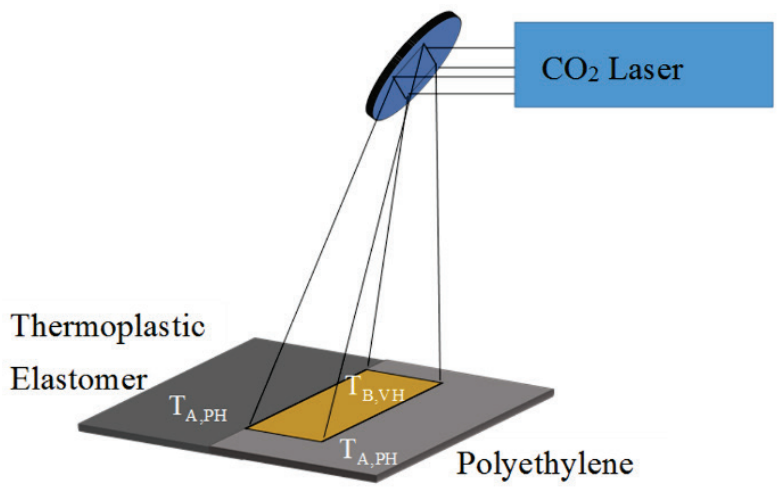

Fig. 2 Process steps of SLBM: Preheating of polymer with higher melting point by $\mathrm{CO}_{2}$ laser
After the preheating temperatures for both materials are achieved, the materials are simultaneously molten in the last process step. For melting the powders, a Digital Light Processing (DLP) chip is used. To illuminate the chip with a rectangular and flat-top beam profile, a DOE is used. The DLP chip acts as flexible mask by which parts of the beam are guided onto the powder bed to melt the powder materials simultaneously. Each of the two million micro mirrors can be tilted between two angles. One angle guides the incident beam onto the powder bed, whereas by the other angle the beam is guided into a beam trap (figure 3 ). After the irradiation, the building platform is lowered by $200 \mu \mathrm{m}$ and a new powder layer is deposited.

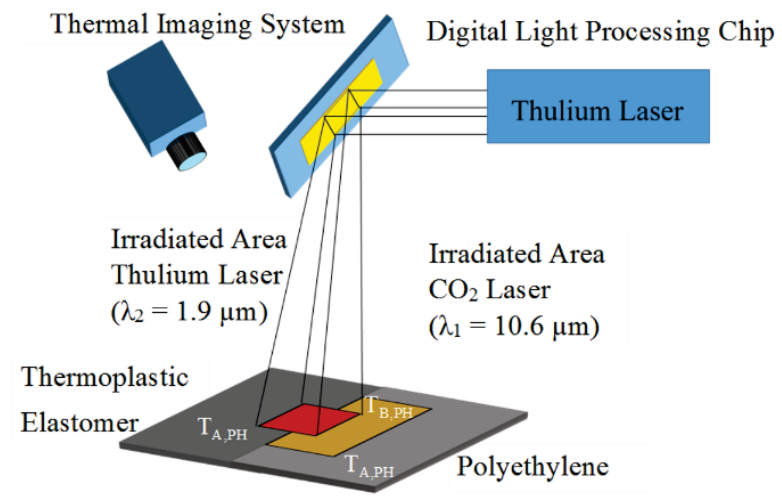

Fig. 3 Process steps of SLBM: Simultaneous energy distribution by thulium laser and DLP chip to melt both materials

The energy deposition and resulting temperatures during the process are controlled by a thermal imaging system with a resolution of $1280 \times 1024$. Due to temperature-dependent changes of the emissivity of the polymers, supposing constant values would lead to incorrect temperature measurements. Therefore, a calibration of the thermal imaging system with thermocouples in a temperature range between room temperature and the respective melting point for the materials is necessary. For manufacturing multi-material parts, the calibration for the polymer with the higher melting point is selected. Therefore, absolute temperatures can only be determined for the higher melting polymer, whereas the temperatures of the other polymer differ due a different emissivity. Furthermore, the temperatures are not quantitatively determinable for melting due to a significant change of emissivity during the phase transition between solid and molten material.

\subsection{Materials}

As powder materials, polyethylene powder (PE, NB5374 Coathylene, DuPont) and a polyamide based thermoplastic elastomer powder (TPE, TPE 210-S, Advanced Laser Materials) are used. Both raw powders show an insufficient flowability for powder deposition in the LBM process and therefore 1.0 weight percent aerosil (Aerosil R106, Evonik) is admixed to the powders. The powders and additives are mixed for 60 minutes by using a turbula mixer. For both, the unmodified and modified 
powders, the Hausner ratio is determined and shown in table $1[11]$.

Table 1 Hausner ration of raw and modified powders

\begin{tabular}{lc}
\hline Particle size & $\begin{array}{c}\mathrm{d} 10 \\
{[\mu \mathrm{m}]}\end{array}$ \\
Material & 1.38 \\
\hline PE (raw powder) & 1.22 \\
PE + 1 wt. \% Aerosil & 1.43 \\
TPE (raw powder) & 1.32 \\
TPE + 1 wt. \% Aerosil &
\end{tabular}

Although for a Haunser ratio less than 1.4 a reduced but sufficient flowability should be expected according to [11], PE raw powder cannot be homogeneously deposited without admixing aerosil. Thus both powders are mixed with aerosil, by which flowability can be significantly increased and a deposition of $200 \mu \mathrm{m}$ thick, dense powder layers is possible. The determined particle size distributions of the powders, which besides the particle geometry influence the flowability are shown in table 2 . Additionally, the melting and crystallization temperature of both materials is determined by a Differential Scanning Calorimetry (DSC) measurement and included in table 2 .

Table 2 Particle size distribution and thermal material characteristics of used materials

\begin{tabular}{lccccc}
\hline Particle size & $\begin{array}{c}\mathrm{d} 10 \\
{[\mu \mathrm{m}]}\end{array}$ & $\begin{array}{c}\mathrm{d} 50 \\
{[\mu \mathrm{m}]}\end{array}$ & $\begin{array}{c}\mathrm{d} 90 \\
{[\mu \mathrm{m}]}\end{array}$ & $\begin{array}{c}\mathrm{T}_{\mathrm{m}} \\
{\left[{ }^{\circ} \mathrm{C}\right]}\end{array}$ & $\begin{array}{c}\mathrm{T}_{\mathrm{c}} \\
{\left[{ }^{\circ} \mathrm{C}\right]}\end{array}$ \\
\hline Material & & & & & \\
+0.25 wt. \% & 35 & 57 & 91 & 128 & 118 \\
Carbon Black & & & & & \\
+1 wt. \% Aerosil & & & & & \\
TPE + 0.25 wt. \% & 38 & 96 & 149 & 135 & 48 \\
Carbon Black & & & & & \\
+1 wt. \% Aerosil & & & & & \\
\hline
\end{tabular}

Besides the flowability, also the optical material properties of the powders are of great importance for the process and thus are determined by an integration sphere measurement setup [6]. For the process, a thulium laser $(\lambda=1.94 \mu \mathrm{m})$ is used to melt both materials. Both materials show a low absorptance at the wavelength of the thulium fibre laser. Because of higher reflectance and transmittance, more laser energy is needed to melt the material, leading to an increase of process time and melting depth. Therefore, the powders are modified by admixing carbon black particles to increase the absorptance. The optical material properties for a layer thickness of $200 \mu \mathrm{m}$ at both wavelengths are shown in table 3. The effect of admixing carbon black as absorption intensifier is clearly visible.

\begin{tabular}{|c|c|c|c|c|}
\hline Table 3 & \multicolumn{4}{|c|}{$\begin{array}{l}\text { Optical material characteristics for a layer } \\
\text { thickness of } 200 \mu \mathrm{m} \text { at a wavelength of } \\
1.94 \mu \mathrm{m}\end{array}$} \\
\hline \multicolumn{2}{|c|}{$\begin{array}{l}\text { Thulium laser } \\
(\lambda=1.94 \mu \mathrm{m})\end{array}$} & Reflectance & $\begin{array}{l}\text { Absorpt- } \\
\text { ance }\end{array}$ & $\begin{array}{l}\text { Trans- } \\
\text { mittance }\end{array}$ \\
\hline \multicolumn{2}{|c|}{$\begin{array}{l}\text { PE } \\
+1 \text { wt. } \% \text { Aerosil }\end{array}$} & 0.39 & 0.30 & 0.31 \\
\hline \multicolumn{2}{|c|}{$\begin{array}{l}\text { TPE } \\
+1 \text { wt. \% Aerosil }\end{array}$} & 0.32 & 0.36 & 0.32 \\
\hline \multicolumn{2}{|c|}{$\begin{array}{l}\text { Thulium laser } \\
(\lambda=1.94 \mu \mathrm{m})\end{array}$} & Reflectance & $\begin{array}{l}\text { Absorpt- } \\
\text { ance }\end{array}$ & $\begin{array}{l}\text { Trans- } \\
\text { mittance }\end{array}$ \\
\hline \multicolumn{2}{|c|}{$\begin{array}{l}\text { PE } \\
+1 \text { wt. \% Aerosil } \\
+0.25 \text { wt. \% } \\
\text { Carbon Black }\end{array}$} & 0.12 & 0.78 & 0.10 \\
\hline \multicolumn{2}{|c|}{$\begin{array}{l}\text { TPE } \\
+1 \text { wt. \% Aerosil } \\
+0.25 \text { wt. \% } \\
\text { Carbon Black }\end{array}$} & 0.15 & 0.69 & 0.16 \\
\hline
\end{tabular}

\subsection{Analysis of part properties}

To allow an analysis of different part properties, five layer parts are built. Besides rectangular part geometries for cross sections, small tensile bars are manufactured to determine tensile strengths. As specimen geometry 1:7 scaled Campus tensile bars are used. The thickness is defined by the height of five layers of the material. The geometry of the specimen is shown in figure 4.
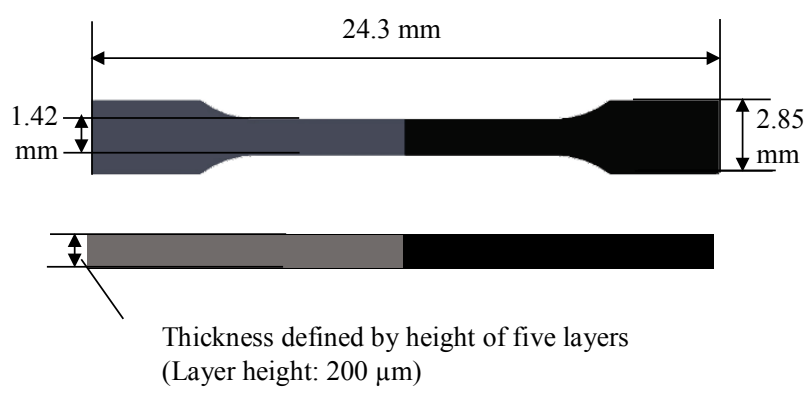

Fig. 4 Geometry of multi-material tensile bars

To discuss the achievable tensile strengths, besides multi-material tensile bars, also the single materials are processed to tensile bars and tested. For statistical interpretation, ten tensile bars are realized.

\section{Results and Discussion}

\subsection{Simultaneous Laser Beam Melting process}

In the case of manufacturing multi-material parts, $\mathrm{PE}$ powder is deposited next to TPE and both materials are heated by infrared-emitters to $115^{\circ} \mathrm{C}$, the preheating temperature of TPE. Although TPE has a higher melting point than PE, the TPE particles already begin to melt at temperatures of $120{ }^{\circ} \mathrm{C}$. Therefore, the global temperature provided by the infrared emitters is set to 
$116{ }^{\circ} \mathrm{C}$ according to TPE as polymer with lower melting point. In order to achieve a homogeneous temperature distribution, the machine is heated for at least five hours. A thermal camera image of the preheated materials is shown in figure 5 .
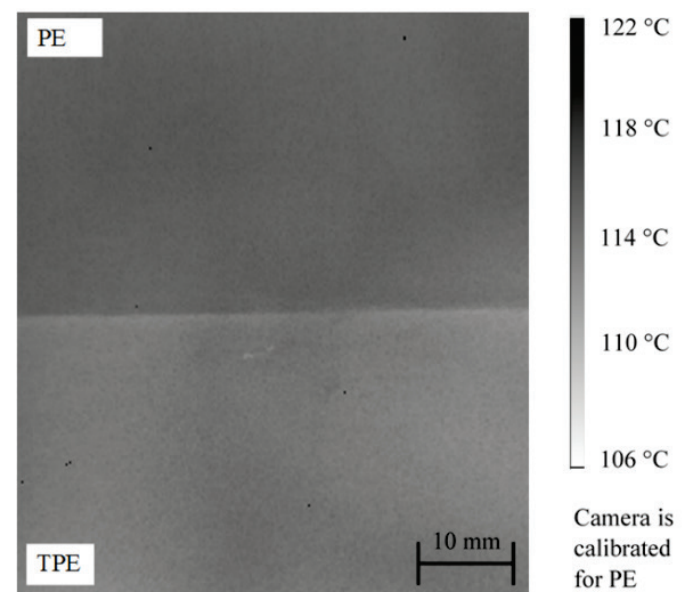

Fig. 5 Global distribution of TPE preheating temperature provided by infrared emitters

In the next step, the $\mathrm{CO}_{2}$ laser irradiates a $30 \mathrm{~mm}$ times $40 \mathrm{~mm}$ area of the PE powder in order to distribute the preheating temperature of $125{ }^{\circ} \mathrm{C}$ for PE (figure 6).

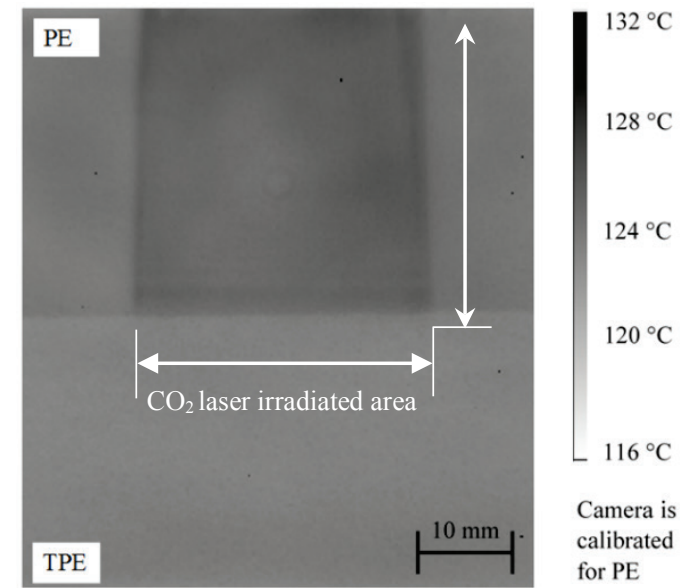

Fig. $6 \quad \mathrm{CO}_{2}$ laser preheats $\mathrm{PE}$

After reaching the preheating temperature for PE, the thulium laser irradiates an area of $35 \mathrm{~mm}$ times $20 \mathrm{~mm}$ with an intensity of $0.2 \mathrm{~mJ} / \mathrm{mm}^{2} \mathrm{~s}$. After $20 \mathrm{~s}$, both powders are completely molten and a new powder layer is deposited. The single steps are repeated until five layers are built on top of each other. The melting process is shown in figure 7.

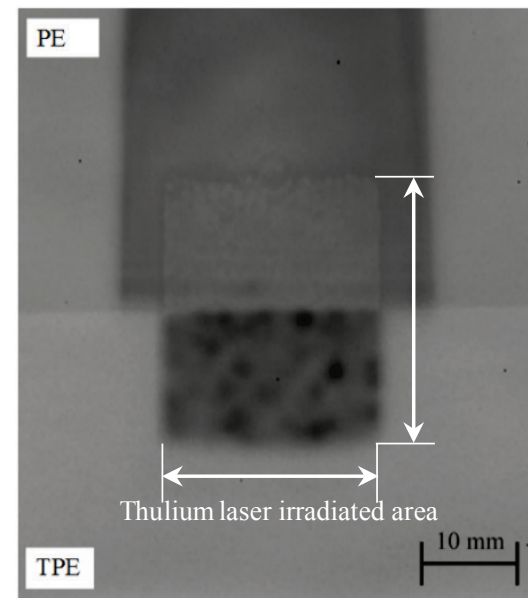

Fig. 7 Simultaneous melting of both powders by thulium laser after $5 \mathrm{~s}$

The DOE used to form a flat-top beam profile out of the Gaussian beam profile does not achieve a completely homogeneous intensity distribution. Thus, local intensity deviations occur and lead to slightly inhomogeneous energy and thus temperature distributions in the powder bed. In these areas, the powder material starts to melt more quickly because higher energy amounts are provided. This effect is intensified by the different optical material characteristics of both powder materials. Therefore, in the TPE powder the intensity variations can be seen more clearly due to a higher absorptance compared to $\mathrm{PE}$ powder (Table 3). If the intensity inhomogeneity has an influence on the part properties needs to be analyzed by cross sections in the following paragraphs.

\subsection{Analysis of part properties}

Important part properties are the porosity, the interlayer connection between different layers and the tensile strengths of the multi-material parts. Figure 8 shows a top-view image of a five-layer TPE-PE part. Although intensity variations occur during the process, the part has a homogeneous surface with a good connection in the boundary zone between both materials.

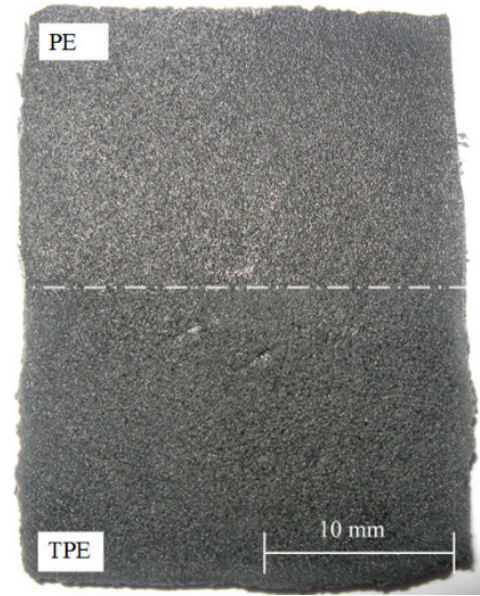

Fig. 8 Top-view image of PE and TPE multi-material part 
To allow a further analysis of the porosity, the interlayer connection and the boundary area, cross sections are prepared. Before the boundary area between both materials is discussed, the single material areas are analyzed. Figure 9 shows a cross section of a five-layer specimen built out of TPE.

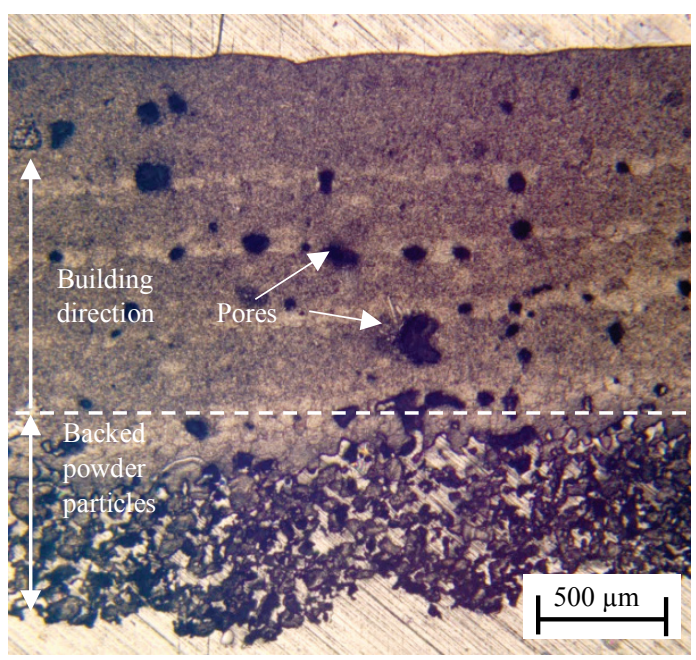

Fig. 9 (a) Cross section of TPE specimen

The porosity without considering the backed powder particles is $7 \%$. The interlayer connection is very good and thus the different layers cannot be distinguished from each other. For a not only qualitative analysis, tensile tests need to be made. As comparison, the cross section of a PE specimen built with the same parameters is shown in figure 10 .

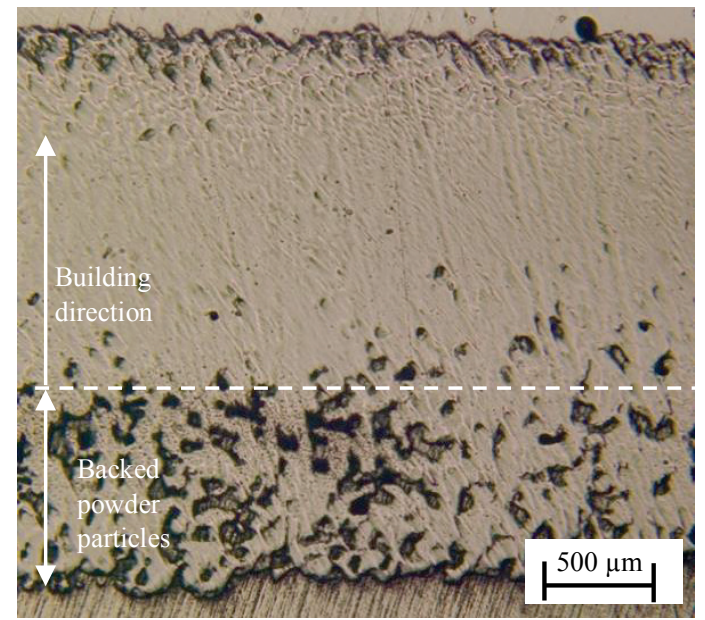

Fig.10 Cross section of PE specimen

The porosity of the PE specimen is only $3 \%$ and therefore significantly lower than for TPE. The reason lies in the different flowability of both powders. Because of the lower flowability of TPE powder due to a higher average particle size and the particle form, the packing density is lower than for the PE powder and therefore more pores occur during the melting and solidifying process [9]. As for TPE, the interlayer connection is also very good and no layer defects are visible.

After discussing the cross sections of the single material areas, the boundary area between both materials, which is shown in figure 11, is analyzed. The boundary area is of great importance for the overall achievable connection between both materials.

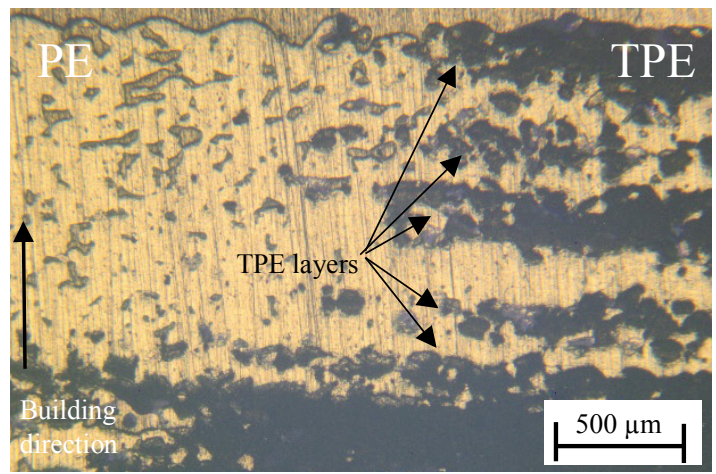

Fig. 11 Cross section of the boundary area between PE and TPE

According to the cross section, the boundary area has no clear separation between both materials. Due to the separation blade of the powder deposition system, the materials seem to be mixed during the powder deposition The five TPE layers are clearly visible, but separated by molten PE. Both materials form a stable connection between the different layers. Overall, the sandwich-like formed contact area between the different materials is significantly enlarged compared to the assumed clearly separated boundary.

Besides a qualitative analysis of the connection by cross sections, the mechanical part properties are analyzed by tensile tests, allowing also a quantitative discussion. Therefore, the tensile strengths of the multimaterial tensile bars are compared to the achievable tensile strengths of single material tensile bars. To allow a statistical interpretation ten tensile bars are built and tested for all materials. The results of the tensile tests are illustrated in figure 12 .

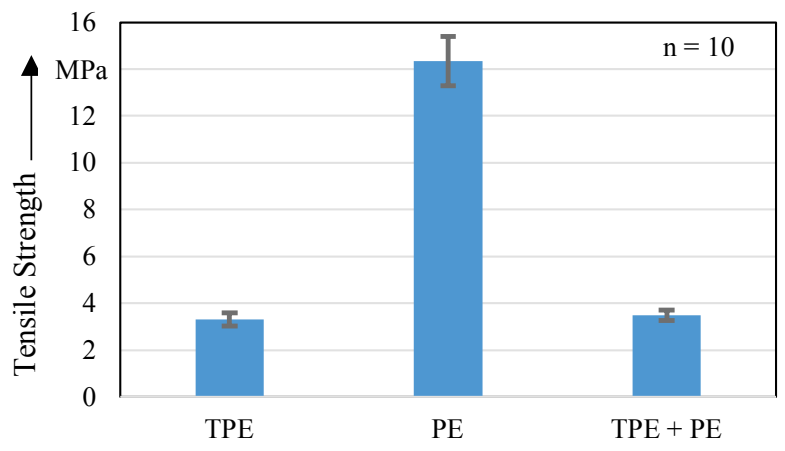

Fig. 12 Tensile strength of single and multi-material tensile bars 
TPE shows a tensile strength of $3.32 \mathrm{MPa}$, whereas the strain at material failure is $303 \%$ due to the high elasticity of the material. The tensile strength of a specimen generated by injection molding has a maximal value of $6 \mathrm{MPa}$ [10]. Compared to TPE, the tensile strength of $\mathrm{PE}$ with $14.34 \mathrm{MPa}$ is significant higher. The strain at material failure is only $4 \%$. For injection molded specimens a maximal tensile strength of $20 \mathrm{MPa}$ would be possible [10]. The tensile strength of the parts realized by SLBM cannot reach the values of parts built by injection molding. Thus, in future works extensive parameter variations need to be done in order to determine the ideal, material-dependent relation between intensity and irradiation time to increase the tensile strength of the parts.

The tensile strength of the multi-material tensile bars lays at $3.48 \mathrm{MPa}$. All multi-material tensile bars break in the TPE side, which is expected as consequence of the single material properties of TPE and proves the good connection stability formed by the mechanical entanglements.

\section{Finite element simulation of the temperature development}

Since the concept of simultaneous energy irradiation for Laser Beam Melting is a new approach, a Finite Element (FE) simulation model is used and refined in order to gain a more profound process understanding. This simulation model bases on the transient nonlinear heat equation including temperature dependent functions for the heat capacity and the heat conduction [8]. The effect of latent heat occurring in the process is also taken into account. The simultaneous irradiation concept is included by a quadratic laser beam shape with homogeneous intensity distribution with an absorption behaviour according to Lambert-Beer's law. A specific matter of the simultaneous irradiation, which is qualitatively affirmed by the simulation, is the influence of the size of the exposure area on the reachable maximum temperatures inside that area when applying identical intensities. This was observed first during experimental measurements which are displayed in Figure 13 showing different quadratic irradiation areas (1, 2, 3, and 4) with different edge lengths w (18 mm (1), 9 $\mathrm{mm}(2), 4 \mathrm{~mm}(3)$, and $2 \mathrm{~mm}$ (4)) but same intensities $\left(0.2 \mathrm{~mJ} / \mathrm{mm}^{2} \mathrm{~s}\right)$ after a irradiation time of $10 \mathrm{~s}$. The irradiation was performed on a PA12 powder bed using the thulium laser and the DLP mirror. The highest temperature $\left(179 \pm 2{ }^{\circ} \mathrm{C}\right)$ is achieved inside quadrat 1 with the largest edge length, while with smaller edge lengths temperatures decrease significantly: $177 \pm 2{ }^{\circ} \mathrm{C}$ (2), $175 \pm 2{ }^{\circ} \mathrm{C}(3)$, and $173 \pm 2{ }^{\circ} \mathrm{C}$ (4). The temperature of the ambient powder was measured to be $172 \pm 2{ }^{\circ} \mathrm{C}$.

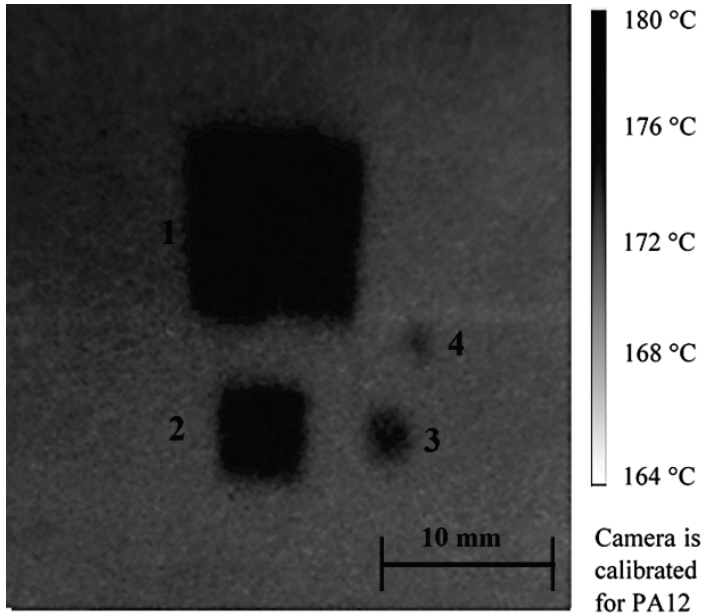

Fig. 13 Temperature distribution recorded by the thermal imaging system after $10 \mathrm{~s}$ : The irradiation of quadratic areas was performed with a homogeneous intensity of $0.2 \mathrm{~mJ} / \mathrm{mm}^{2} / \mathrm{s}$ on a PA12 powder bed using the thulium laser and the DLP mirror

The observed behaviour is confirmed by the simulation qualitatively. For the simulations, quadratic irradiation shapes with edge lengths $\mathrm{w}$ of $1,2,3$, and 4 $\mathrm{mm}$ could be calculated in appropriate time. Further parameters are the irradiation intensity of $3.6 \mathrm{~mJ} / \mathrm{mm}^{2} \mathrm{~s}$, the preheating temperature of $178{ }^{\circ} \mathrm{C}$, and the reflectance of 0.5 and the absorption coefficient of $53681 / \mathrm{m}$ which both were derived from measurements by integration spheres using the thulium laser $(\lambda=1.94 \mu \mathrm{m})$ and PA12 [6]. The irradiation intensity was chosen higher than in the experiments to assure a clear temperature increase in the simulation for the comparable small edge length $\mathrm{w}$

The simulation results for a quadratic-shaped beam with an edge length of $2 \mathrm{~mm}$ are exemplary displayed in Figure 14a. The calculated temporal behavior of the achieved maximum temperature for the different edge lengths is plotted in the Figure 14b. 


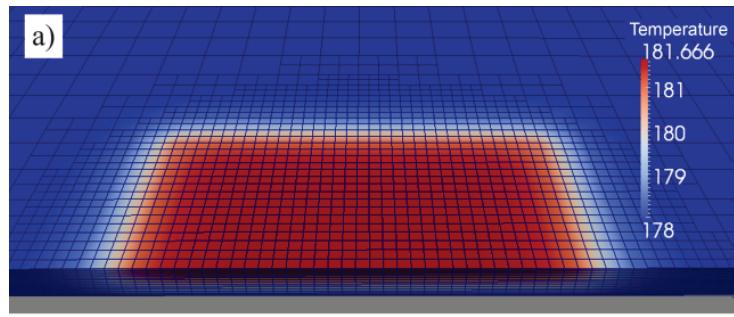

b)

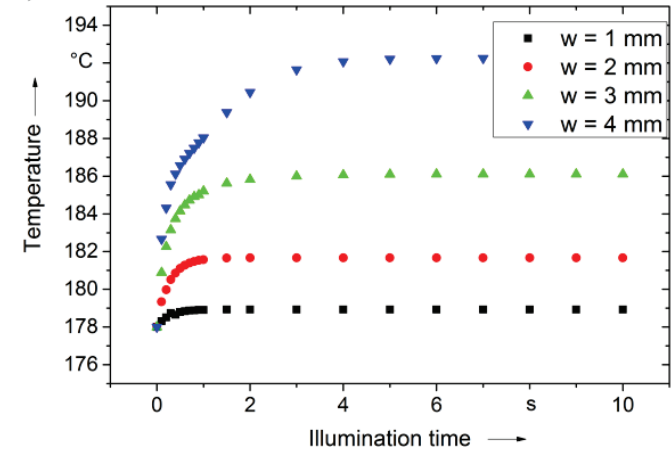

Fig. 14 Results from the FE simulation model: (a) Temperature distribution with intersection for a quadratic-shaped beam with an edge length of $2 \mathrm{~mm}$ and (b) temporal behavior of the maximum temperature during irradiation by a quadratic-shaped beam with different edge lengths $\mathrm{w}$ at $\mathrm{a}$ homogeneous irradiation intensity of $3.6 \mathrm{~mJ} / \mathrm{mm}^{2} \mathrm{~s}$

The simulation results show that after a short period of temperature increase a constant temperature level is reached. The time period of the increase and the saturation level depend clearly on the edge length. Both rise with increasing edge length. The highest saturation temperature of $192.3{ }^{\circ} \mathrm{C}$ is achieved for an edge length of $4 \mathrm{~mm}$, while with smaller edge lengths temperatures are significantly lower: $186.1^{\circ} \mathrm{C}(\mathrm{w}=3 \mathrm{~mm}), 181.7^{\circ} \mathrm{C}(\mathrm{w}=$ $2 \mathrm{~mm})$, and $178.9{ }^{\circ} \mathrm{C}(\mathrm{w}=1 \mathrm{~mm})$. This seems to be reasonable, since more energy is induced into the material for larger edge lengths or irradiation shapes.

The simulative proof of the dependence between the size of the exposure area and the reachable maximum temperatures inside that area when applying identical intensities shows that heat conduction and energy loss at the interface between powder surface and air plays a key role in the simultaneous irradiation concept. Both influences lead to differently intense heat accumulation inside the irradiation area at different exposure area sizes. With respect to the application of arbitrarily shaped irradiation areas, these results are disadvantageous since a homogeneous intensity would not provide a homogeneous temperature distribution when differently delicate shapes are included. Thus, solutions are required in the future in order to optimize out coming results of the SLBM concept.

First, it is possible to reduce the irradiation time which would diminish the time-dependent heat diffusion. Therefore, powerful laser sources with suitable components or better efficiency of the irradiation system are required.
A second approach which will be investigated in the future is the spatial intensity adaption to compensate different amount of heat losses. This can be easily achieved using the DLP chip since its single mirrors can not only provide on (black) and off (white) modes but also grey scale modes which are realized by fast switching between on and off modes. Therefore, the thermal imaging system will be used for regulation.

\section{Conclusion}

Multi-material parts are manufactured out of TPE and PE powder by Simultaneous Laser Beam Melting. By this new technology different polymer materials can be processed within a single process to multi-material parts, enlarging the field of application of Additive Manufacturing in the future. Besides showing the different process steps, the achieved parts are analyzed regarding their porosity and interlayer connection by cross sections. Especially the area between both materials is of great interest and does not show a clear separated boundary. Instead, the materials are mixed due to turbulences during the powder deposition and form a sandwich-like boundary area. To allow a quantitative analysis of the connection between the materials, additionally tensile bars are built and tested. The results show that failure always occurs in the area of the material with weaker tensile strength, in this case TPE, but not in the boundary area between both materials. The detailed influence of the boundary area on the joint stability has to be analyzed in future works. Moreover, the influence of the exposure area size on the reachable maximum temperatures inside that area when applying identical intensities is investigated by experiments and a FE simulation model. The results show that heat diffusion and energy loss at the interface between powder surface and air lead to varying maximum temperatures despite the homogeneous intensity input. The compensation of such variation using the DLP mirror will be investigated in future works.

\section{Acknowledgments}

The German Research Foundation (DFG) in the collaborative research centre "SFB 814 Additive Fertigung" has supported this research.

\section{References}

[1] C. Deckhard: U.S. Patent 4,863,538 (1986) (Patent)

[2] G. Levy, R. Schindel, J.-P. Kruth: CIRP Annals Manufacturing Technology (2003)

[3] S. Vinodh, S. Devadasan, S. Maheskumar: International Journal of Advanced Manufacturing Technologies, 46 (2010)

[4] V. Petrovica: International Journal of Production Research, 49, Issue 4 (2011) 
[5] T. Stichel, T. Laumer, P. Amend, M. Schmidt: Proceedings of the Polymer Processing Society 29th Annual Meeting. (2013)

[6] T. Laumer, T. Stichel, P. Amend, M. Schmidt: High Value Manufacturing, pp. 255-260. (2013)

[7] T. Laumer, T. Stichel, A. Gachot, P. Amend, M. Schmidt: Proceedings of the Polymer Processing Society 29th Annual Meeting (2013)

[8] D. Riedlbauer, M. Drexler, D. Drummer, P. Steinmann, J. Mergheim: Modelling, simulation and experimental validation of heat transfer in selective laser melting of the polymeric material PA12. In: Computational Materials Science, pp. 239-248 (2014)

[9] Y. Shi, Z. Li, H. Sun, S. Huang, F. Zeng: Effect of the properties of the polymer materials on the quality of selective laser sintering parts. In: Proc. Instn Mech. Engrs Part L: J. Materials: Design and Applications, Vol. 218 (2004)

[10] H. Domininghaus, P. Elsner, P. Eyerer, T. Hirth: Kunststoffe - Eigenschaften und Anwendungen. Springer Verlag, Berlin (2008)

[11] VDI Richtlinie 3405: Additive Fertigungsverfahren . Lasersintern von Kunststoffbauteilen Güteüberwachung, Berlin (2013)

(Received: June 13, 2014, Accepted: February 5, 2015) 